\title{
EXTENDING THE POSTHARVEST LIFE OF UNREFRIGERATED AVOCADO (PERSEA AMERICANA MILL.) FRUIT BY STORAGE IN POLYETHYLENE BAGS
}

\author{
G.R. CHAPLIN* and M.G. HAWSON** \\ *CSIRO, Division of Food Research, P.O. Box 52, North Ryde, N.S.W., 2113 (Australia) \\ **Department of Agriculture, Jarrah Road, South Perth, W.A., 6151 (Australia)
}

\begin{abstract}
Chaplin, G.R. and Hawson, M.G., 1981. Extending the postharvest life of unrefrigerated avocado (Persea americana Mill.) fruit by storage in polyethylene bags. Scientia . Hortic., 14: 219-226.

Mature 'Hass' avocado (Persea americana Mill.) fruit were enclosed in sealed polyethylene bags and stored at ambient temperatures for different times. Modified atmospheres developed inside the bags and fruit stayed firm and apparently non-ripening while they remained enclosed. Storage time and temperature influenced ripening of fruits after they were removed from bags. Most storage treatments resulted in an extension to the total postharvest life of fruits compared to control fruits which were not stored in such bags. Abnormal ripening characteristics were observed when storage temperature was high and storage time exceeded 8 days.
\end{abstract}

\section{INTRODUCTION}

The time taken by harvested mature avocado fruit to become ripe, i.e. soft and edible, is regulated by the interaction between endogenous fruit factors and postharvest environmental conditions. The later in the season that mature fruit are harvested, the less time they take to ripen (Adato and Gazit, 1974b), but the rate of ripening is inversely related to endogenous calcium levels in the fruit (Tingwa and Young, 1974). After harvest, water-deficit stress (Adato and Gazit, 1974a) and treatment with exogenous ethylene $\left(\mathrm{C}_{2} \mathrm{H}_{4}\right)$ (Gazit and Blumenfeld, 1970) accelerates the initiation of ripening, but low temperature causes a marked retardation in ripening rate (Aharoni et al., 1968). Hence, when there is little or no control of the postharvest environmental conditions, the shelf life of avocado fruit becomes difficult to predict and serious problems of marketing may result.

Although temperature control is generally regarded as the most effective means of extending the postharvest life of perishable fruit, refrigerated post- 
harvest handling facilities are not available in many countries. Under these circumstances, and where distances between production districts and consumption centres are large, considerable wastage may occur from the premature ripening of fruit in transit.

While avocados are susceptible to chilling injury when stored below about $10^{\circ} \mathrm{C}$ (Zauberman et al., 1977), previous studies (Hatton and Reeder, 1972; Spalding and Reeder, 1972) showed that avocados remain firm for longer and have better quality if stored at low temperature in controlled atmospheres rather than in air. Similarly, quality after storage was improved when sealed polyethylene bags were used as the containers at low temperatures (Oudit and Scott, 1973; Scott and Chaplin, 1978).

In the present work, the use of sealed polyethylene bags to store avocados for different times at ambient temperatures is investigated.

\section{EXPERIMENTAL}

\section{Controlled temperature storage -- experiment 1}

Uniform mature 'Hass' avocado (Persea americana Mill.) fruit were obtained from the Sunraysia district near Mildura, Victoria, and single fruit were enclosed in sealed polyethylene bags ( $50 \mu \mathrm{m}$ thickness) within $1 \mathrm{~h}$ of picking. Transport of the fruit to the laboratory at ambient temperature $\left(15-20^{\circ} \mathrm{C}\right)$ required another $20 \mathrm{~h}$. On arrival, treatment groups of five replicate fruit were stored in constant-temperature rooms held at 20 and $30^{\circ} \mathrm{C}$ for 0 (control), 4, 6, 8 and 11 days to simulate a range of postharvest transportation regimes. At the end of each storage period, the gas composition inside the bags was determined by gas chromatography (Scott et al., 1970). The fruit were then transferred to individual gas-tight respiration jars (1.25 l) ventilated with a constant flow of $\mathrm{C}_{2} \mathrm{H}_{4}$-free air at $20^{\circ} \mathrm{C}$, and allowed to ripen. The concentrations of $\mathrm{CO}_{2}$ in the effluent air were measured every $12 \mathrm{~h}$ with a Grubb Parsons IR gas analyser.

\section{Trial shipment - experiment 2}

Mature 'Hass' avocados from the Sunraysia district near Mildura, Victoria, were picked on two dates 5 days apart and randomized to the following treatments: (1) control (air storage); (2) stored singly in sealed polyethylene bags ( $50 \mu \mathrm{m}$ thickness); (3) stored as in treatment (2) together with an ethylene absorbent (vermiculite/cement block, approximately $60 \times 30 \times 10$ $\mathrm{mm}$, impregnated with a saturated solution of $\mathrm{KMnO}_{4}$ ). The storage unit was a single fruit and each treatment was replicated 20 times.

After the second harvest, all fruits were packed in standard fibreboard trays and transported to Perth by unrefrigerated road transport. On arrival, the gas composition inside the bags was determined. The fruit were then removed from the bags and allowed to ripen in air at approximately $25^{\circ} \mathrm{C}$. 
Transit time from Mildura to Perth, a distance of approximately $3000 \mathrm{~km}$, was 5 days. Hence, two storage times ( 5 and 10 days) were achieved. Ripe fruits were determined by manual assessment of softness.

In both experiments, avocado ripening was regarded as the strictly postharvest event which renders fruit into an edible form in which softening was the key indicator. In the text, "ripening" and "softening" and their derivatives are used as interchangeable terms.

\section{RESULTS AND DISCUSSION}

\section{Storage atmospheres and fruit condition}

The levels of $\mathrm{CO}_{2}, \mathrm{O}_{2}$ and $\mathrm{C}_{2} \mathrm{H}_{4}$ in polyethylene bags at the end of storage result from the interaction of the gas exchange activity of the enclosed fruit and the gas diffusion characteristics of the polyethylene film (Cowell and Scott, 1962). Although the modified atmospheres are in dynamic equilibrium with the fruit and the external atmosphere, a relatively stable atmosphere of $\mathrm{CO}_{2}$ and $\mathrm{O}_{2}$ was achieved within $5 \mathrm{~h}$ after avocados were sealed inside bags. In Experiment 1 (Table I), storage time and temperature did not affect the $\mathrm{O}_{2}$ concentrations in bags and the $\mathrm{CO}_{2}$ concentrations only differed after 11 days storage. In contrast, $\mathrm{C}_{2} \mathrm{H}_{4}$ concentrations were very variable. Although mean values were not different after storage, very high $\mathrm{C}_{2} \mathrm{H}_{4}$ concentrations were measured (up to $30 \mathrm{ppm}$ ) in some individual samples after 8 and 11 days storage. This result could be explained as an increased rate of synthesis resulting in a net $\mathrm{C}_{2} \mathrm{H}_{4}$ accumulation inside the bags. The variability of this apparent $\mathrm{C}_{2} \mathrm{H}_{4}$ response is similar to that found in the onset of the $\mathrm{C}_{2} \mathrm{H}_{4}$ climacteric of avocados ripened normally in air.

The levels of gases measured in bags of fruit held at ambient temperature in Experiment 2 were not different whether stored for 5 or 10 days (Table II).

\section{TABLE I}

Effect of storage time and temperature on gas composition surrounding avocado fruit in sealed polyethylene bags (Experiment I)

\begin{tabular}{|c|c|c|c|c|c|c|c|}
\hline \multirow{3}{*}{$\begin{array}{l}\text { Storage time } \\
\text { (days) }\end{array}$} & \multicolumn{7}{|c|}{ Gas concentration at each temperature $\left({ }^{\circ} \mathrm{C}\right)^{*}$} \\
\hline & \multicolumn{2}{|c|}{$\mathrm{CO}_{2}(\%)$} & \multicolumn{2}{|c|}{$\mathrm{O}_{2}(\%)$} & \multicolumn{3}{|c|}{$\mathrm{C}, \mathrm{H}_{4}(\mathrm{ppm})$} \\
\hline & 20 & 30 & 20 & 30 & 20 & 30 & \\
\hline 4 & 7.6 & 7.5 & 4.2 & 6.2 & 0.1 & 1.6 & \\
\hline 6 & 8.0 & 8.1 & 4.9 & 2.4 & 0.3 & 1.1 & $\therefore$ \\
\hline 8 & 7.7 & 6.5 & 4.3 & 2.4 & 12.7 & 2.3 & \\
\hline 11 & 8.9 & 6.6 & 4.1 & 2.9 & 6.7 & 0.4 & \\
\hline
\end{tabular}

*The least significant difference (at the $5 \%$ level) for mean $\mathrm{CO}_{2}$ values was

1.7. Significant differences between the $\mathrm{O}_{2}$ values and $\mathrm{C}_{2} \mathrm{H}_{4}$ values were not detected. 


\section{TABLE II}

Effect of storage time and treatment on gas composition surrounding avocado fruit in sealed polyethylene bags (Experiment 2)

\begin{tabular}{lclll}
\hline Storage treatment & $\begin{array}{l}\text { Storage time } \\
\text { (days) }\end{array}$ & \multicolumn{3}{l}{ Gas concentration* } \\
\cline { 3 - 5 } & & $\mathrm{CO}_{2}(\%)$ & $\mathrm{O}_{2}(\%)$ & $\mathrm{C}_{2} \mathrm{H}_{4}(\mathrm{ppm})$ \\
\hline Polyethylene bag & 5 & 9.4 & 3.6 & 0.6 \\
& 10 & 9.2 & 5.9 & 0.5 \\
Polyethylene bag + & 5 & & & \\
ethylene absorbent & 10 & 1.9 & 3.9 & 0.5 \\
& & 2.0 & 4.4 & 2.5 \\
\hline
\end{tabular}

*The least significant difference (at the $5 \%$ level) for mean $\mathrm{CO}_{2}$ values was 0.7 .

Significant differences between the $\mathrm{O}_{2}$ values and $\mathrm{C}_{2} \mathrm{H}_{4}$ values were not detected.

The presence or absence of $\mathrm{C}_{2} \mathrm{H}_{4}$ absorbent had no effect on $\mathrm{O}_{2}$ and $\mathrm{C}_{2} \mathrm{H}_{4}$ levels, but $\mathrm{CO}_{2}$ levels were significantly less in bags having absorbent blocks. Evidently this reduction was due to the absorption of $\mathrm{CO}_{2}$ by the fresh cement blocks. Although there were no differences in the mean $\mathrm{C}_{2} \mathrm{H}_{4}$ levels in the presence or absence of absorbent blocks, some individual replicates showed large accumulations of $\mathrm{C}_{2} \mathrm{H}_{4}$ after 10 days storage. Previous experience has shown that $\mathrm{KMnO}_{4}$ impregnated blocks eventually become ineffective in maintaining low $\mathrm{C}_{2} \mathrm{H}_{4}$ levels due to the depletion of oxidising capacity. It is assumed that this depletion is accelerated at high temperatures.

\section{Fruit firmness after storage}

Control fruit softened and were fully ripe approximately 8 days after harvest in both experiments. However, all of the enclosed fruit were firm and had a freshly picked appearance at the end of storage irrespective of the storage time. Since the duration of several of the storage treatments equalled or exceeded the ripening time of controls, it was concluded that storage in modified atmospheres at ambient temperatures could effectively delay the commencement of softening. Although these data did not indicate an optimum storage atmosphere composition, it was shown that a wide range of atmospheres (viz., mean values of $2-9 \% \mathrm{CO}_{2}$ and $2-6 \% \mathrm{O}_{2}$ ) was effective. However, it cannot be claimed that other changes associated with ripening were similarly delayed.

\section{Poststorage respiration and fruit ripening}

The effect of storage time and temperature (Experiment 1) on the respiration patterns of fruit after removal from bags is shown in Fig. 1. In avocados stored for 4 and 6 days at $30^{\circ} \mathrm{C}$ (Fig. $1 \mathrm{a}$ and $\mathrm{b}$ ), the respiratory rise began 


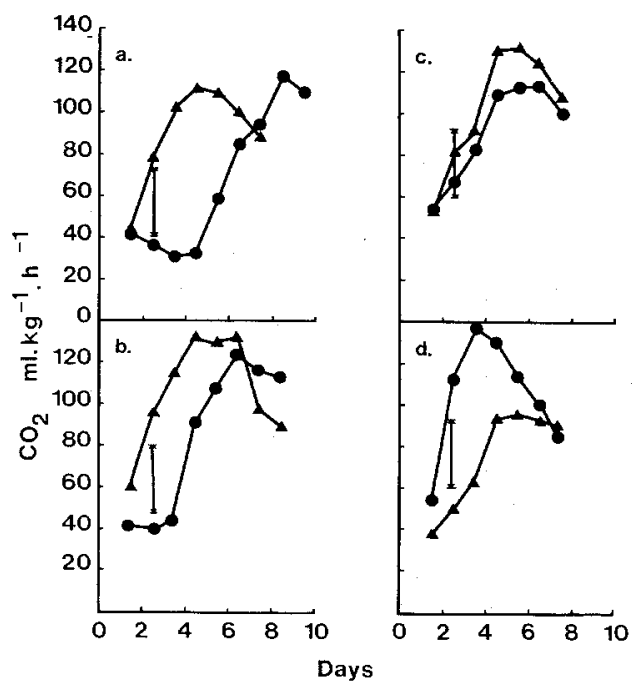

Fig. 1. Respiration patterns of fruit after removal from storage in polyethylene bags. Results are averages of five fruits (replicates) with the least significant difference (at $5 \%$ level) indicated by the vertical bars. a, Four days storage; $b, 6$ days storage; $c, 8$ days

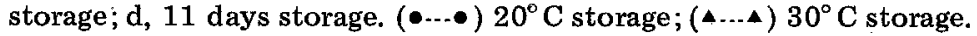

soon after the fruit were transferred to the respiration jars, but the rise was delayed in the fruit which had been stored at $20^{\circ} \mathrm{C}$. There was no lag in the onset of the respiratory rise of the fruit stored for 8 days (Fig. 1c) and the respiration rates were not different for fruit from both storage temperatures. However, after 11 days storage (Fig. 1d), the respiratory rise of the fruit stored at $30^{\circ} \mathrm{C}$ was delayed and depressed compared with fruit stored at $20^{\circ} \mathrm{C}$. This suggests that the respiration response was impaired when the fruit were stored for this length of time at the higher temperature.

In this experiment, fruit were considered ripe at the time of maximum respiration rate and this was confirmed by manual assessment of fruit softness. The time from the end of storage to maximum respiration rate was therefore termed the apparent ripening time (ART). The relationship between storage treatment and ART is shown in Fig. 2. The ART of fruit stored at $30^{\circ} \mathrm{C}$ was not affected by storage time, but at $20^{\circ} \mathrm{C}$, the ART decreased significantly as storage time increased.

The effect of storage on the total postharvest life (TPHL) of fruit is shown in Fig. 3. This term was derived from the sum of storage time and ART. In this comparison, the TPHL of the fruit at $20^{\circ} \mathrm{C}$ was approximately 12 days, irrespective of storage time. In effect, the contribution of increased storage time was cancelled out by the corresponding decrease in the ART shown in Table I. However, with storage at $30^{\circ} \mathrm{C}$, the TPHL increased significantly with, and was a function of, storage time and ranged between 8.6 and 16 days. Since the ART (or TPHL) of control fruit was 8.2 days, all fruit stored at the lower temperature had a TPHL gain of at least 3 days. However, for fruit 

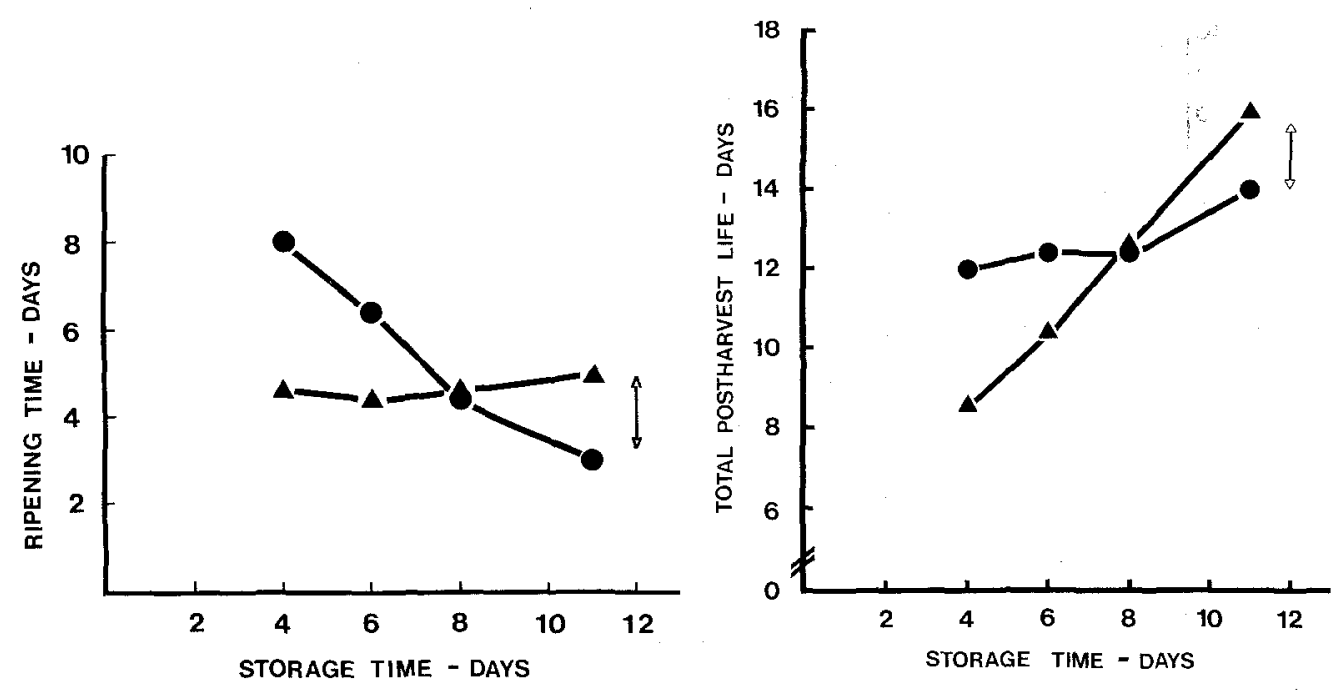

Fig. 2. Effect of storage time in polyethylene bags on the apparent ripening time of avocado fruit. Each mean is the average of five fruits (replicates) with the least significant difference $\left(5 \%\right.$ level) indicated by the vertical bar. $(\bullet \cdots \bullet) 20^{\circ} \mathrm{C}$ storage; $(\bullet \cdots) 30^{\circ} \mathrm{C}$ storage.

Fig. 3. Effect of storage time in polyethylene bags on the total postharvest life of avocado fruit. Each mean is the average of five fruits (replicates) with the least significant difference $\left(5 \%\right.$ level) indicated by the vertical bar. $(\bullet \ldots \bullet) 20^{\circ} \mathrm{C}$ storage; $(\wedge \ldots \wedge) 30^{\circ} \mathrm{C}$ storage. TPHL of control fruit, 8.2 days.

stored at the higher temperature, there was no net advantage to TPHL unless storage time exceeded 4 days.

In the second experiment, the TPHL of fruit in each treatment was calculated as above when fruit had ripened (manual assessment). These data are summarised in Table III. Although all bagged fruit were firm at the end of each storage treatment, softening was detected in control fruit by 5 days after picking and was complete by 8 days. No effect on the rate of softening

\section{TABLE III}

Effect of storage time and treatment on the total postharvest life (TPHL) of stored avocados

\begin{tabular}{llr}
\hline $\begin{array}{l}\text { Storage time } \\
\text { (days) }\end{array}$ & Treatment & TPHL (days) \\
\hline 5 & Control & 8 \\
5 & Polyethylene bag & 11 \\
5 & Polyethylene bag $+\mathrm{KMnO}_{4}$ & 11 \\
10 & Control* & 8 \\
10 & Polyethylene bag & 16 \\
10 & Polyethylene bag $+\mathrm{KMnO}_{4}$ & 16 \\
\hline
\end{tabular}

\footnotetext{
* Oversoft at first examination.
} 
(ART) of previously bagged fruit was observed. The presence of $\mathrm{C}_{2} \mathrm{H}_{4}$ absorbent during storage had no effect on the ART or TPHL. This result could be expected since the absorbent did not significantly alter the $\mathrm{C}_{2} \mathrm{H}_{4}$ concentration in bags of stored fruit (Table II).

It is shown in Table III that the ART of stored fruit is the same for both storage times, and TPHL is a function of storage time. This agrees with the result in the first experiment (Fig. 2) for fruit stored at the high temperature. Monitoring of temperature during the course of this experiment was not possible, although daily maxima were in the range $34-40^{\circ} \mathrm{C}$.

Since the control fruit in this experiment had commenced to soften while in transit, avocados transported in a similar way under commercial conditions would therefore have decreased market value due to premature softening and be subject to wastage. The extension to TPHL achieved by storage of fruit in polyethylene bags during transportation could be expected to prevent such losses within certain limits since avocados are prevented from softening while enclosed in bags. In the fruits stored for 10 days, there was evidence of abnormal ripening and postharvest rots developed in several fruit after removal from bags. It was considered that a storage/transit time of 10 days was too long for the adoption of this storage technique when fruit were subjected to the ambient temperature regime which prevailed during this experiment. Ripening abnormalities were also reported by Zauberman et al. (1977) when avocados were stored at high temperatures. However, fruit stored for shorter periods at such high temperatures could be expected to ripen satisfactorily after removal of storage bags. Alternatively, considerably longer storage times (hence TPHL) might be achieved for rot-free avocados stored at a moderate ambient temperature (viz. $20^{\circ} \mathrm{C}$ ).

\section{ACKNOWLEDGEMENTS}

Thanks are expressed to Mr. J.C. Abell of Citrusland Packers, Buronga, for the supply of experimental fruit and to Ms M. Willcox, CSIRO Division of Mathemathics and Statistics, for statistical analysis of data. We also thank Mr. D. McE. Alexander, CSIRO Division of Horticultural Research, for assistance in setting up of experiments.

\section{REFERENCES}

Adato, I. and Gazit, S., 1974a. Water-deficit stress, ethylene production, and ripening in avocado fruits. Plant Physiol., 53: 45-46.

Adato, I. and Gazit, S., $1974 \mathrm{~b}$. Postharvest response of avocado fruits of different maturity to delayed ethylene treatments. Plant Physiol., 53: 899-902.

Aharoni, Y., Schiffmann-Nadel, M. and Zaubermann, G., 1968. Effects of gradually decreasing temperatures and polyethylene wraps on the ripening and respiration of avocado fruit. Isr. J. Agric. Res., 18: 77-82.

Cowell, N.D. and Scott, K.J., 1962. The variability of atmospheres produced by fruit stored in polyethylene box liners. J. Hortic. Sci., 37: 87-93.

Gazit, S. and Blumenfeld, A., 1970. Response of mature avocado fruits to ethylene treatments before and after harvest. J. Am. Soc. Hortic. Sci., 95: 229-231. 
Hatton, T.T. and Reeder, W.F., 1972. Quality of 'Lula' avocados stored in controlled atmospheres with or without ethylene. J. Am. Soc. Hortic. Sci., 97: 339-341.

Oudit, D.D. and Scott, K.J., 1973. Storage of 'Hass' avocados in polyethylene bags. Trop. Agric. (Trinidad), 50: 241-243.

Scott, K.J., McGlasson, W.B. and Roberts, E.A., 1970. Potassium permanganate as an ethylene absorbent in polyethylene bags to delay ripening of bananas during storage. Aust. J. Exp. Agric. Anim. Husb., 10: 237-240.

Scott, K.J. and Chaplin, G.R., 1978. Reduction of chilling injury in avocados stored in sealed polyethylene bags. Trop. Agric. (Trinidad), 55: 87-90.

Spalding, D.H. and Reeder, W.F., 1972. Quality of 'Booth 8' and 'Lula' avocados stored in a controlled atmosphere. Fla. State Hortic. Soc., 85: 337-341.

Tingwa, P.O. and Young, R.E., 1974. The effect of calcium on the ripening of avocado (Persea americana Mill.) fruits. J. Am. Soc. Hortic. Sci., 99: 540-542.

Zaubermann, G., Schiffmann-Nadel, M. and Yanko, U., 1977. The response of avocado fruits to different storage temperatures. HortScience, 12: 353-354. 